\title{
Article \\ Effect of Selected Cooking Ingredients for Nixtamalization on the Reduction of Fusarium Mycotoxins in Maize and Sorghum
}

\author{
Julianah Olayemi Odukoya ${ }^{1,2,3} \mathbb{1}$, Sarah De Saeger ${ }^{1,2, *(\mathbb{C}}$, Marthe De Boevre ${ }^{2}\left(\mathbb{D}\right.$, Gabriel Olaniran Adegoke ${ }^{4}$,

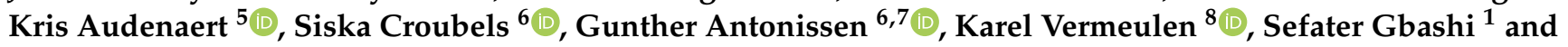 \\ Patrick Berka Njobeh ${ }^{1, *(1)}$
}

check for

updates

Citation: Odukoya, J.O.; De Saeger,

S.; De Boevre, M.; Adegoke, G.O.;

Audenaert, K.; Croubels, S.;

Antonissen, G.; Vermeulen, K.;

Gbashi, S.; Njobeh, P.B. Effect

of Selected Cooking Ingredients for

Nixtamalization on the Reduction of Fusarium Mycotoxins in Maize and

Sorghum. Toxins 2021, 13, 27.

https://doi.org/10.3390/toxins

13010027

Received: 26 November 2020

Accepted: 29 December 2020

Published: 4 January 2021

Publisher's Note: MDPI stays neutral with regard to jurisdictional clai$\mathrm{ms}$ in published maps and institutional affiliations.

Copyright: $\odot 2021$ by the authors. Licensee MDPI, Basel, Switzerland. This article is an open access article distributed under the terms and conditions of the Creative Commons Attribution (CC BY) license (https:// creativecommons.org/licenses/by/ $4.0 /)$.
1 Department of Biotechnology and Food Technology, Faculty of Science, University of Johannesburg, Doornfontein Campus, P.O. Box 17011, Gauteng 2028, South Africa; julianahodukoya@gmail.com (J.O.O.); sgbashi@uj.ac.za (S.G.)

2 Centre of Excellence in Mycotoxicology and Public Health, Department of Bioanalysis, Faculty of Pharmaceutical Sciences, Ghent University, 9000 Ghent, Belgium; marthe.deboevre@ugent.be

3 Department of Food Science and Technology, Kwara State University, Malete P.M.B. 1530, Kwara State, Nigeria

4 Department of Food Technology, Faculty of Technology, University of Ibadan, Ibadan 200284, Nigeria; goadegoke@yahoo.com

5 Department of Plants and Crops, Faculty of Bioscience Engineering, Ghent University, 9000 Ghent, Belgium; Kris.Audenaert@ugent.be

6 Department of Pharmacology, Toxicology and Biochemistry, Faculty of Veterinary Medicine, Ghent University, Salisburylaan 133, 9820 Merelbeke, Belgium; Siska.Croubels@ugent.be (S.C.); Gunther.Antonissen@ugent.be (G.A.)

7 Department of Pathology, Bacteriology and Avian Diseases, Faculty of Veterinary Medicine, Ghent University, Salisburylaan 133, 9820 Merelbeke, Belgium

8 Department of Data Analysis and Mathematical Modelling, Faculty of Bioscience Engineering, Ghent University, 9000 Ghent, Belgium; KarelB.Vermeulen@ugent.be

* Correspondence: Sarah.DeSaeger@ugent.be (S.D.S.); pnjobeh@uj.ac.za (P.B.N.)

Abstract: Although previous studies have reported the use of nixtamalization for mycotoxins reduction in maize, the efficacy of calcium hydroxide and other nixtamalization cooking ingredients for mycotoxin reduction/decontamination in sorghum and other cereals still need to be determined. The current study investigated the effect of five nixtamalization cooking ingredients (wood ashes, calcium hydroxide, sodium hydroxide, potassium hydroxide, and calcium chloride) on the reduction of Fusarium mycotoxins in artificially contaminated maize and sorghum using liquid chromatographytandem mass spectrometry. All tested cooking ingredients effectively reduced levels of mycotoxins in the contaminated samples with reduction initiated immediately after the washing step. Except for the calcium chloride nixtamal, levels of fumonisin $\mathrm{B}_{1}, \mathrm{~B}_{2}$, and $\mathrm{B}_{3}$ in the processed sorghum nixtamal samples were below the limit of detection. Meanwhile, the lowest $\mathrm{pH}$ values were obtained from the maize $(4.84 ; 4.99)$, as well as sorghum $(4.83 ; 4.81)$ nejayote and nixtamal samples obtained via calcium chloride treatment. Overall, the results revealed that the tested cooking ingredients were effective in reducing the target mycotoxins. In addition, it pointed out the potential of calcium chloride, though with reduced effectiveness, as a possible greener alternative cooking ingredient (ecological nixtamalization) when there are environmental concerns caused by alkaline nejayote.

Keywords: cooking ingredients; food safety; Fusarium mycotoxins; LC-MS/MS; maize; nixtamalization; sorghum; food processing

Key Contribution: The study revealed the potential of other nixtamalization cooking ingredients (sodium hydroxide, potassium hydroxide, and calcium chloride), aside from the commonly used calcium hydroxide, for the reduction of mycotoxins in maize and sorghum during nixtamalization. Moreover, it pinpoints calcium chloride as an alternative cooking ingredient for nixtamalization when there are environmental concerns. 


\section{Introduction}

Mycotoxins are secondary fungal metabolites that often contaminate agricultural commodities in the field or during storage [1-4]. The fungal species producing these mycotoxins are particular members of the Fusarium, Aspergillus, Penicillium, and Alternaria genera that pose serious health-related challenges in humans as a result of their toxigenic characteristics $[5,6]$. Fusarium mycotoxins, such as fumonisin $\mathrm{B}_{1}\left(\mathrm{FB}_{1}\right)$, fumonisin $\mathrm{B}_{2}\left(\mathrm{FB}_{2}\right)$, fumonisin $\mathrm{B}_{3}\left(\mathrm{FB}_{3}\right)$, deoxynivalenol (DON), 3-acetyl deoxynivalenol (3-ADON), 15-acetyl deoxynivalenol (15-ADON), nivalenol (NIV), and zearalenone (ZEN), among others [7], are of serious concern as they cause economic losses, trade barrier and human health problems like anorexia, diarrhea, cancer, and immunosuppression [1,8].

Nixtamalization is a major processing procedure employed in the preparation of some maize-based products including masa, tortillas, tortilla chips, and pozole [9]. It is a special food-processing technique in that it can cause several physicochemical modifications to maize kernels, contribute to flavor and affect mycotoxins whereby the latter (i.e., mycotoxins) might be degraded, modified, or released/bound in food [10].

In line with Escalante-Aburto [11], this processing technique (nixtamalization) can be grouped into three categories, namely, classic, traditional (involving the commonly used calcium hydroxide and other nixtamalization cooking ingredients), and alternative technologies. The classic nixtamalization, used in Mexico and Central America, involves the application of wood ashes [12] substituted with lime in traditional nixtamalization to ensure higher levels of pericarp removal [11]. Several authors, including Figueroa et al. [13], Ramírez-Jiménez et al. [14], Ramírez-Araujo et al. [15], and Enríquez-Castro et al. [16] have reported the use of lime as a traditional nixtamalization process, which according to Schaarschmidt and Fauhl-Hassek [10] is an effective as well as a promising technique for reducing mycotoxins while enhancing nutrient availability in maize. Nonetheless, the use of calcium hydroxide has been linked with environmental pollution issues arising from the disposal of its by-product, nejayote (wastewater), which usually has a high $\mathrm{pH}$ [17]. Other alkaline ingredients for nixtamalization, such as sodium hydroxide and potassium hydroxide, have also been used in the food industry [12]. For instance, sodium hydroxide is used to pre-cook grains for pozole preparation [12,18]. Based on environmental pollution issues caused by conventional nixtamalization, ecological nixtamalization, an alternative technology involving the use of calcium salts such as calcium chloride, calcium sulfate, and calcium carbonate, has been proposed with a reduced $\mathrm{pH}$ of the residual solution as a key advantage [11].

Although cereals like maize and sorghum contain essential nutrients [19], they are susceptible to natural contamination by toxigenic fungi accompanied by the production of mycotoxins [20,21]. This study, a MycoSafe-South project, thus, investigated the effect of some selected cooking ingredients for nixtamalization (wood ashes, calcium hydroxide, sodium hydroxide, potassium hydroxide, and calcium chloride) on the reduction of Fusarium mycotoxins in artificially-contaminated maize and sorghum grains during nixtamalization. The study is of immense importance as most investigations involving the use of calcium hydroxide during nixtamalization for mycotoxins reduction focused solely on maize with none on sorghum. Besides, no study has been carried out to establish the effect of wood ashes, sodium hydroxide, potassium hydroxide, and calcium chloride on the reduction of Fusarium mycotoxins in maize and sorghum during nixtamalization.

\section{Results and Discussion}

\subsection{Influence of Different Nixtamalization Cooking Ingredients on Fusarium Mycotoxins during Nixtamalization of Maize}

In this study, the effect of nixtamalization processing steps on Fusarium mycotoxins during the production of nixtamalized maize and sorghum was investigated. The substrate (maize and sorghum grains) used as starting materials were tested and had Fusarium mycotoxins concentrations below the limit of detection (LOD) (Table 1). After artificial inoculation with toxigenic Fusarium verticillioides, six toxins $\left(\mathrm{FB}_{1}, \mathrm{FB}_{2}, \mathrm{FB}_{3}, \mathrm{DON}\right.$, NIV, 
and ZEN; Table 2) were detected in the maize samples confirming this cereal as an ideal medium for the production of the targeted Fusarium mycotoxins [22].

Table 1. Estimated percentage recovery, limit of detection, and quantification ( $\mu \mathrm{g} / \mathrm{kg})$ of Fusarium mycotoxins in maize and sorghum following LC-MS/MS analysis.

\begin{tabular}{ccccccc}
\hline Mycotoxins & $\begin{array}{c}\text { Maize } \\
\text { LOD }\end{array}$ & $\begin{array}{c}\text { Maize } \\
\text { LOQ }\end{array}$ & $\begin{array}{c}\text { Maize } \\
\text { Recovery }\end{array}$ & $\begin{array}{c}\text { Sorghum } \\
\text { LOD }\end{array}$ & $\begin{array}{c}\text { Sorghum } \\
\text { LOQ }\end{array}$ & $\begin{array}{c}\text { Sorghum } \\
\text { Recovery }\end{array}$ \\
\hline $\mathrm{FB}_{1}$ & 1.0 & 2.9 & 100.0 & 0.8 & 2.4 & 107.0 \\
$\mathrm{FB}_{2}$ & 0.6 & 1.7 & 99.0 & 0.2 & 0.7 & 1.6 \\
$\mathrm{FB}_{3}$ & 0.6 & 1.7 & 102.0 & 0.5 & $\mathrm{~N} / \mathrm{A}$ & $\mathrm{N} / \mathrm{N}$ \\
$\mathrm{DON}$ & 3.1 & 9.2 & 102.0 & $\mathrm{~N} / \mathrm{A}$ & $\mathrm{A}$ & $\mathrm{N} / \mathrm{A}$ \\
$\mathrm{NIV}$ & 3.5 & 10.6 & 99.0 & $\mathrm{~N} / \mathrm{A}$ & $\mathrm{N} / \mathrm{A}$ & $\mathrm{N} / \mathrm{A}$ \\
$\mathrm{ZEN}$ & 1.1 & 3.5 & 107.0 & $\mathrm{~N}$ & \\
\hline
\end{tabular}

N/A: Not applicable; LOD: Limit of detection; LOQ: Limit of quantification; $\mathrm{FB}_{1}$ : fumonisin $\mathrm{B}_{1} ; \mathrm{FB}_{2}$ : fumonisin $\mathrm{B}_{2} ; \mathrm{FB}_{3}$ : fumonisin $\mathrm{B}_{3}$; DON: deoxynivalenol; NIV: nivalenol; and ZEN: zearalenone.

Table 2. Concentrations of Fusarium mycotoxins in purchased maize, inoculated maize, and washed maize and estimated percentage reduction after washing following LC-MS/MS analysis.

\begin{tabular}{|c|c|c|c|c|}
\hline $\begin{array}{l}\text { Fusarium } \\
\text { Mycotoxins }\end{array}$ & $\begin{array}{c}\text { Purchased Maize } \\
(\mu \mathrm{g} / \mathrm{kg})\end{array}$ & $\begin{array}{c}\text { Inoculated Maize } \\
(\mu \mathrm{g} / \mathrm{kg})\end{array}$ & $\begin{array}{l}\text { Washed Maize } \\
\quad(\mu \mathrm{g} / \mathrm{kg})\end{array}$ & $\begin{array}{l}\text { Reduction } \\
\quad(\% \mathrm{R})\end{array}$ \\
\hline $\mathrm{FB}_{1}$ & $<\mathrm{LOD}$ & $2470.5^{b} \pm 346.4$ & $661.5^{a} \pm 243.6$ & 73.2 \\
\hline $\mathrm{FB}_{2}$ & $<\mathrm{LOD}$ & $604.7^{b} \pm 84.9$ & $204.6^{a} \pm 79.7$ & 66.0 \\
\hline $\mathrm{FB}_{3}$ & $<\mathrm{LOD}$ & $409.0^{b} \pm 59.5$ & $162.9^{\mathrm{a}} \pm 24.8$ & 60.0 \\
\hline Total FBs & $<\mathrm{LOD}$ & $3884.3^{b} \pm 482.0$ & $1029.0^{\mathrm{a}} \pm 344.3$ & 73.5 \\
\hline DON & $<\mathrm{LOD}$ & $330.9^{b} \pm 17.6$ & $224.3^{\mathrm{a}} \pm 67.9$ & 32.3 \\
\hline NIV & $<\mathrm{LOD}$ & $104.9 \pm 15.5$ & $<$ LOD & 100.0 \\
\hline ZEN & $<\mathrm{LOD}$ & $15.9^{\mathrm{a}} \pm 2.5$ & $15.0^{\mathrm{a}} \pm 4.9$ & 6.2 \\
\hline
\end{tabular}

Values are the means of five replicates \pm standard error. Means followed by different letters are significantly different $(p<0.05)$. LOD: Limit of detection; $\mathrm{FB}_{1}$ : fumonisin $\mathrm{B}_{1} ; \mathrm{FB}_{2}$ : fumonisin $\mathrm{B}_{2} ; \mathrm{FB}_{3}$ : fumonisin $\mathrm{B}_{3}$; Total $\mathrm{FBs}$ : $\mathrm{FB}_{1}+\mathrm{FB}_{2}+\mathrm{FB}_{3} ; \mathrm{DON}$ : deoxynivalenol; $\mathrm{NIV}$ : nivalenol; and ZEN: zearalenone.

According to Karlovsky et al. [23], water-soluble mycotoxins, including DON [24], may be removed by washing the outer layer of grains, while Humpf and Voss [25] noted that the water-solubility characteristics of fumonisin mycotoxins such as $\mathrm{FB}_{1}, \mathrm{FB}_{2}$, and $\mathrm{FB}_{3}$ determine the rate at which they may be affected by grain washing. In this experiment, washing of the inoculated maize samples led to a significant reduction $(p<0.05)$ in the levels of the detected mycotoxins except for ZEN, where there was no statistically significant difference $(p=0.74)$ in the mycotoxin content before and after washing (Table 2). NIV was completely depleted at this stage, which reflects its high solubility in water as pointed out by Karlovsky et al. [23]. Similarly, the low solubility of ZEN in water also explains the non-significant difference $(p>0.05)$ of this mycotoxin in the washed and unwashed samples. Generally, results of the mycotoxin levels obtained after washing are in agreement with the predicted solubility values for $\mathrm{FB}_{1}$ and $\mathrm{FB}_{2}(>20,000 \mathrm{mg} / \mathrm{L})$, DON $(36,000 \mathrm{mg} / \mathrm{L})$, NIV (64,600 mg/L), and ZEN (117 mg/L) previously established by Karlovsky et al. [22]. In addition, the total fumonisin reduction by washing $(74 \%)$ was found to be in line with that obtained in previous studies by Humpf and Voss [26] (73\%), Matumba et al. [27], as well as Shetty and Bhat [28] (74\%).

Cooking is a major thermal processing step during nixtamalization [12]. The results obtained after cooking showed that potassium hydroxide was the most effective cooking ingredient for the reduction of $\mathrm{FB}_{1}, \mathrm{FB}_{2}, \mathrm{FB}_{3}$, and $\mathrm{DON}$, while $\mathrm{ZEN}$ was most effectively reduced by calcium hydroxide treatment (Figures 1 and 2). Park et al. [29] pinpointed potassium hydroxide as a feasible compound for alkaline hydrolysis of FBs. The concentration of ZEN found below the LOD in maize samples cooked with calcium hydroxide indicates that in addition to the isomerization of trans-ZEN to cis-ZEN in maize, this cooking ingredient 
attacked the lactone ring of ZEN, leading to the degradation of ZEN into an undetectable biotransformation product(s) [10].

For the steeping step, calcium chloride was found to be the least effective in reducing $\mathrm{FB}_{1}$ and $\mathrm{ZEN}$. Moreover, calcium chloride in addition to wood ashes gave the least reduction for DON. This suggests that incomplete dehulling involved in the use of calcium chloride [11] led to a decrease in the reduction of fumonisins (FBs) content. The research outcome is consistent with Fandohan [30] who observed that removal of pericarp, referred to as dehulling, brought about a reduction in FBs concentrations. The ineffectiveness of wood ashes for the reduction of DON, with respect to other alkaline cooking ingredients, supports the point made by Santiago et al. [12] that wood ashes mainly consist of calcium carbonate with a lower alkaline $\mathrm{pH}$ value as compared to calcium hydroxide, sodium hydroxide, or potassium hydroxide. All cooking ingredients tested gave similar reduction results for $\mathrm{FB}_{2}$; however, the alkaline cooking ingredients gave the highest $\mathrm{FB}_{3}$ reduction levels in maize. To an extent, this agrees with Schaarschmidt and Fauhl-Hassek [10] findings where it was reported that alkaline cooking allows the leaching of FBs into the water during maize steeping. In addition, according to Santiago et al. [12], wood ashes contain traces of calcium hydroxide which, in a way, explains the non-significant difference in the potential of wood ashes and calcium hydroxide to reduce $\mathrm{FB}_{3}$. In the final nixtamal (after rinsing and drying), calcium chloride had the least reducing effect on all Fusarium mycotoxins in maize but there was no statistically significant difference in the ability of all the tested nixtamalization cooking ingredients to reduce ZEN. Ryu et al. [31] earlier noted that the use of chemical treatments for ZEN reduction in foods has not recorded any desired result.

As shown in Figure 1 and in line with Schaarschmidt and Fauhl-Hassek [10], the incomplete mycotoxins reduction recorded after rinsing and drying step in some instances (wood ashes and calcium chloride- $-\mathrm{FB}_{2}$; wood ashes, potassium hydroxide and calcium chloride $-\mathrm{FB}_{3}$ ) may be due to the release of mycotoxins from matrix components of maize, which depends on the processing condition. This also explains the decreased percentage reduction for ZEN in the final nixtamal following potassium hydroxide treatment after rinsing and drying when compared to that obtained after steeping (Figure 2).

Although the accumulation of hydrolyzed and biotransformed products was not investigated in this study, it is important to note that there is a possibility of the presence of modified mycotoxins in the final nixtamal as a result of the solubility, changes in the structure, and molecular masses of the parent mycotoxins [32]. According to these authors, i.e., Freire and Sant'Ana [32], these modified mycotoxins produced via processing may be toxic to human health.

\subsection{Influence of Different Nixtamalization Cooking Ingredients on Fusarium Mycotoxins during Nixtamalization of Sorghum}

Assessment of the influence of the selected cooking ingredients on Fusarium mycotoxins $\left(\mathrm{FB}_{1}, \mathrm{FB}_{2}\right.$, and $\mathrm{FB}_{3}$; Table 3$)$ contents during sorghum nixtamalization process was performed using artificially contaminated sorghum samples. Results showing the effect of washing on the reduction of target mycotoxins in the fungal-inoculated sorghum samples are highlighted in Table 3. 

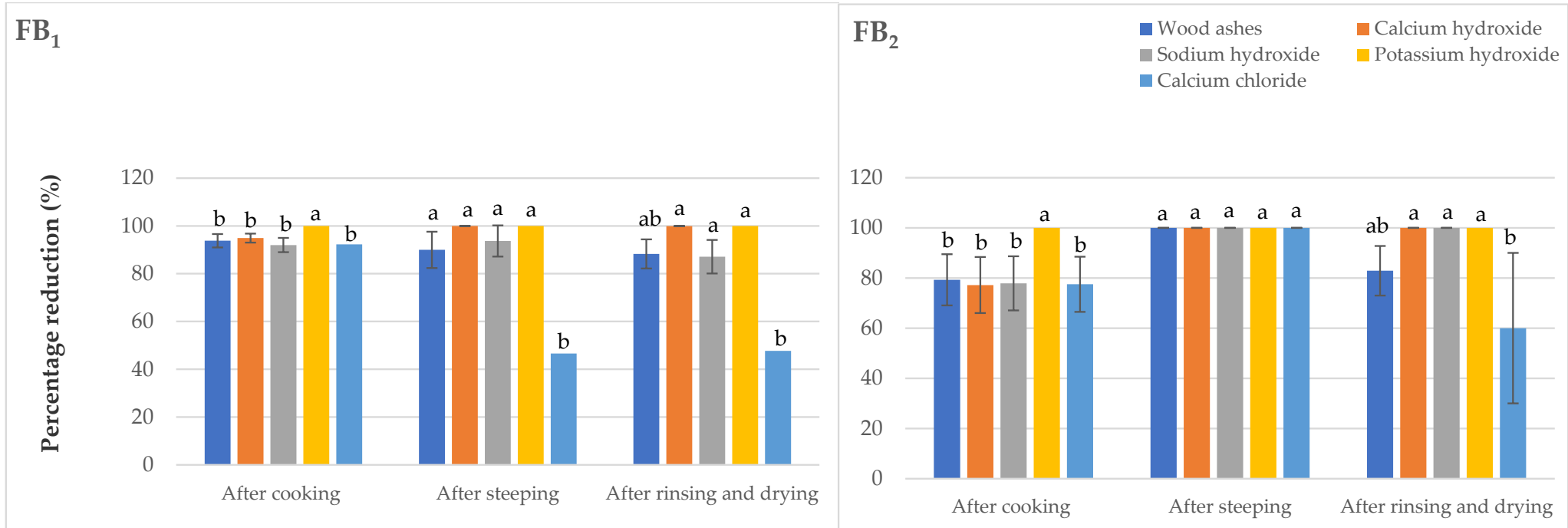

$\mathrm{FB}_{3}$

\section{Total FBs}
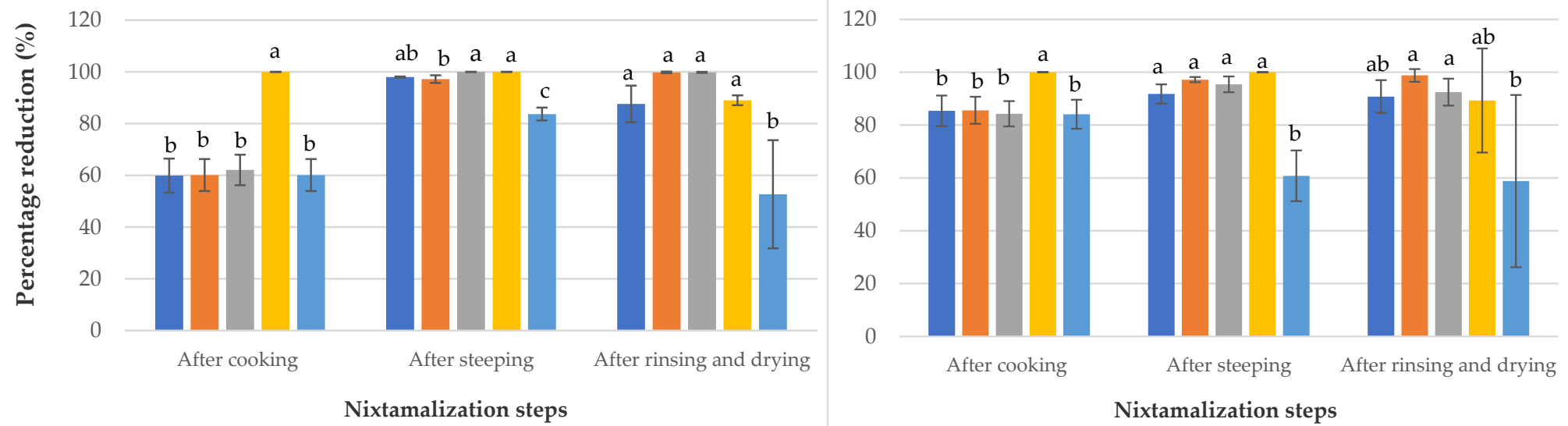

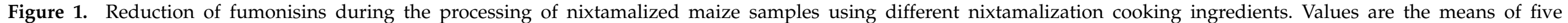
replicates \pm standard error. Means followed by different letters are significantly different $(p<0.05)$ according to Tukey post-hoc test. 

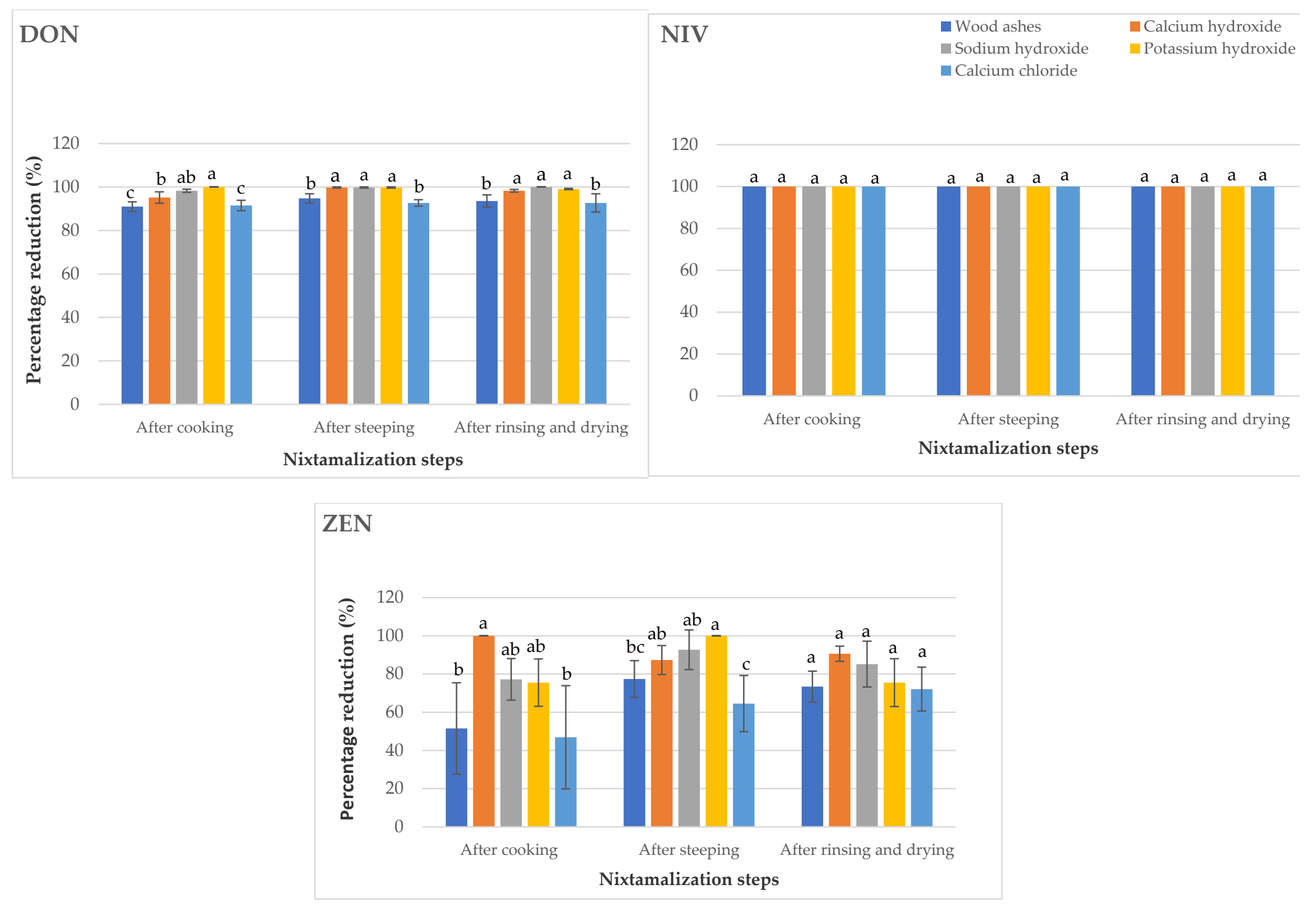

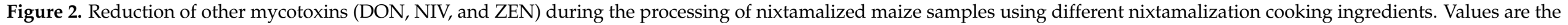
means of five replicates \pm standard error. Means followed by different letters are significantly different $(p<0.05)$ according to Tukey post-hoc test. 
Table 3. Concentrations of Fusarium mycotoxins in purchased sorghum, inoculated sorghum, washed sorghum, and estimated percentage reduction after washing following LC-MS/MS analysis.

\begin{tabular}{ccccc}
\hline $\begin{array}{c}\text { Fusarium } \\
\text { Mycotoxins }\end{array}$ & $\begin{array}{c}\text { Purchased Sorghum } \\
(\boldsymbol{\mu g} / \mathbf{k g})\end{array}$ & $\begin{array}{c}\text { Inoculated Sorghum } \\
(\boldsymbol{\mu g} / \mathbf{k g})\end{array}$ & $\begin{array}{c}\text { Washed Sorghum } \\
(\boldsymbol{\mu g} / \mathbf{k g})\end{array}$ & $\begin{array}{c}\text { Reduction } \\
(\% \mathbf{R})\end{array}$ \\
\hline $\mathrm{FB}_{1}$ & $<\mathrm{LOD}$ & $816.7^{\mathrm{b}} \pm 346$ & $416.5^{\mathrm{a}} \pm 244$ & 49.0 \\
$\mathrm{FB}_{2}$ & $<\mathrm{LOD}$ & $1079.3^{\mathrm{b}} \pm 134.3$ & $362^{\mathrm{a}} \pm 159.6$ & 66.4 \\
$\mathrm{FB}_{3}$ & $<\mathrm{LOD}$ & $1364.8^{\mathrm{b}} \pm 196.8$ & $563.3^{\mathrm{a}} \pm 212.5$ & 58.7 \\
Total FBs & $<\mathrm{LOD}$ & $3260.9^{\mathrm{b}} \pm 397.3$ & $1341.8^{\mathrm{a}} \pm 365.3$ & 58.8 \\
\hline
\end{tabular}

Values are the means of five replicates \pm standard error. Means followed by different letters are significantly different $(p<0.05)$. LOD: Limit of detection; $\mathrm{FB}_{1}$ : fumonisin $\mathrm{B}_{1} ; \mathrm{FB}_{2}$ : fumonisin $\mathrm{B}_{2} ; \mathrm{FB}_{3}$ : fumonisin $\mathrm{B}_{3}$; and Total $\mathrm{FBs}$ : $\mathrm{FB}_{1}+\mathrm{FB}_{2}+\mathrm{FB}_{3}$.

The reduced levels of these FBs after washing indicate that they are water-soluble and are easily washed away from the outer layer of the sorghum grains [23]. Schaarschmidt and Fauhl-Hassek [10] also reported that FBs are soluble and prone to leaching from grains into steeping and cooking solutions. Interestingly, there was no statistically significant difference $(p>0.05)$ in the results obtained from the effect of wood ashes, calcium hydroxide, sodium hydroxide, and potassium hydroxide during steeping, rinsing, and cooking stages on the reduction of FBs in sorghum. Calcium chloride, however, had the least potential for the reduction of these toxins (Figure 3).

As earlier mentioned, the use of calcium chloride involves partial dehulling [11], which affects its effectiveness for mycotoxins reduction in food when compared to other alkaline cooking ingredients that ensure better pericarp removal [17]. As discovered in this study, higher levels of FBs' reduction were recorded in the nixtamalized sorghum compared to those of maize. These observations may be attributed to the absence of a waxy layer in sorghum grain that allowed the rapid uptake of water [33].

\subsection{Effect of Different Nixtamalization Cooking Ingredients on the $\mathrm{pH}$ Values of Obtained Nejayote and Nixtamal}

Disposal of highly alkaline wastewater, nejayote ( $\mathrm{pH}$ 9-12) remains a huge concern for food industries that process food by nixtamalization [34]. The nejayote and nixtamal from maize after calcium chloride treatment were found to have lower $\mathrm{pH}$ values ( 4.84 and 4.99 , respectively), which were significantly different $(p<0.05)$ from those in the samples ( $\mathrm{pH}$ range: 9.09-11.67 to 6.71-8.81) obtained via other cooking ingredients (Figure 4A). This is somewhat similar to the research findings of Pappa et al. [35] where the nejayote obtained from lime had a $\mathrm{pH}$ of 12. It can, thus, be seen that calcium chloride, a form of ecological nixtamalization, contributes minimally to environmental pollution when compared to other tested nixtamalization cooking ingredients [11,12].

Calcium chloride treatment also gave the lowest $\mathrm{pH}$ values in sorghum negayote ( $\mathrm{pH} 4.83$ ) and nixtamal ( $\mathrm{pH} 4.81$ ) samples. Interestingly, $\mathrm{pH}$ values of the sorghum nejayote and nixtamal samples after treatment with the different cooking ingredients followed a similar pattern recorded for maize, i.e., calcium hydroxide $>$ sodium hydroxide $>$ potassium hydroxide $>$ wood ashes $>$ calcium chloride (Figure 4B). This suggests that in comparison to other cooking ingredients, the use of calcium chloride for the production of sorghum nixtamal would raise the least concerns with respect to the problem of environmental pollution [11]. 


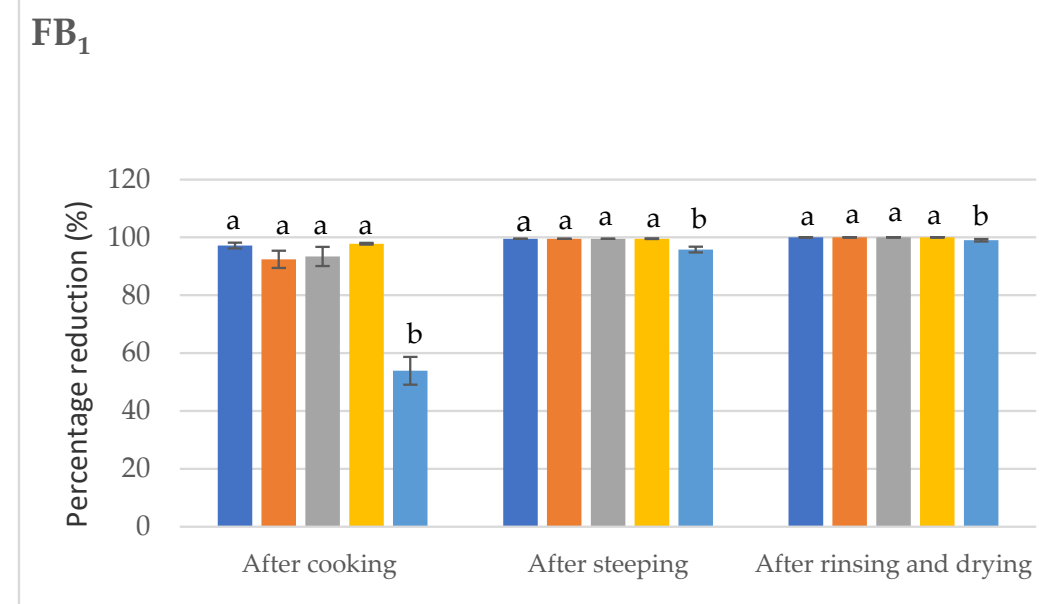

$\mathrm{FB}_{3}$

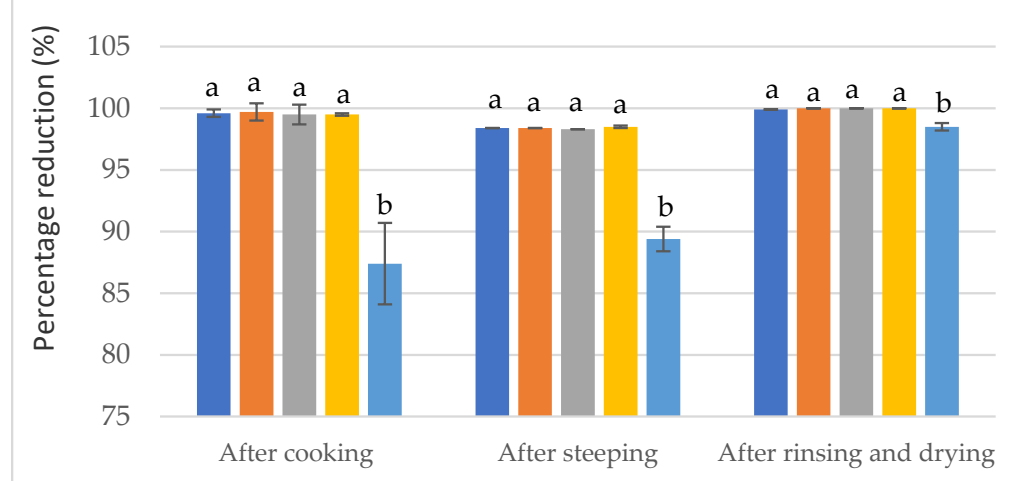

Nixtamalization steps

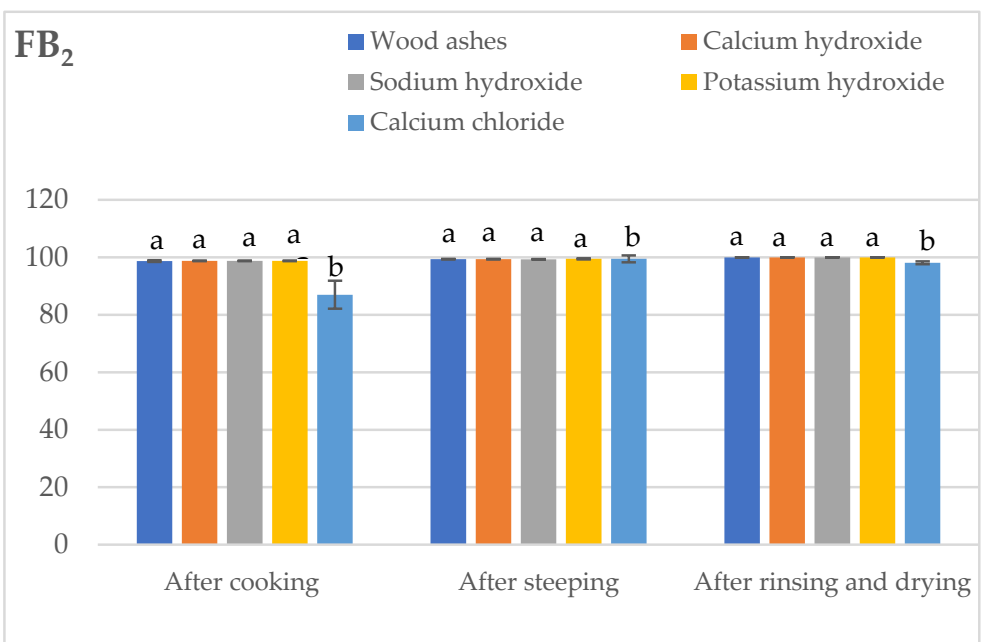

Total FBs

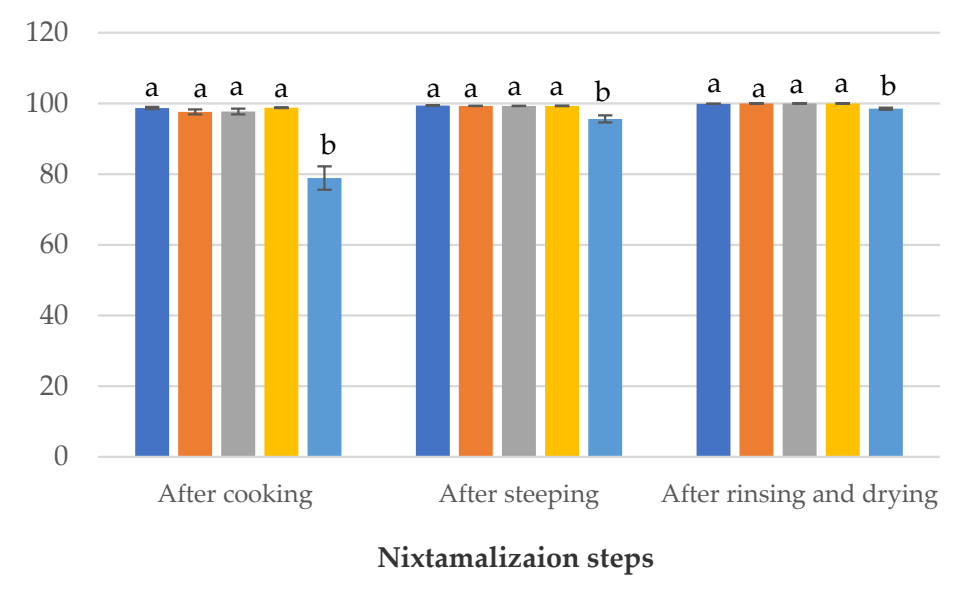

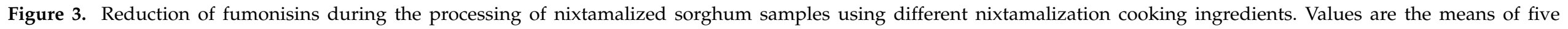
replicates \pm standard error. Means followed by different letters are significantly different $(p<0.05)$ according to Tukey post-hoc test. 


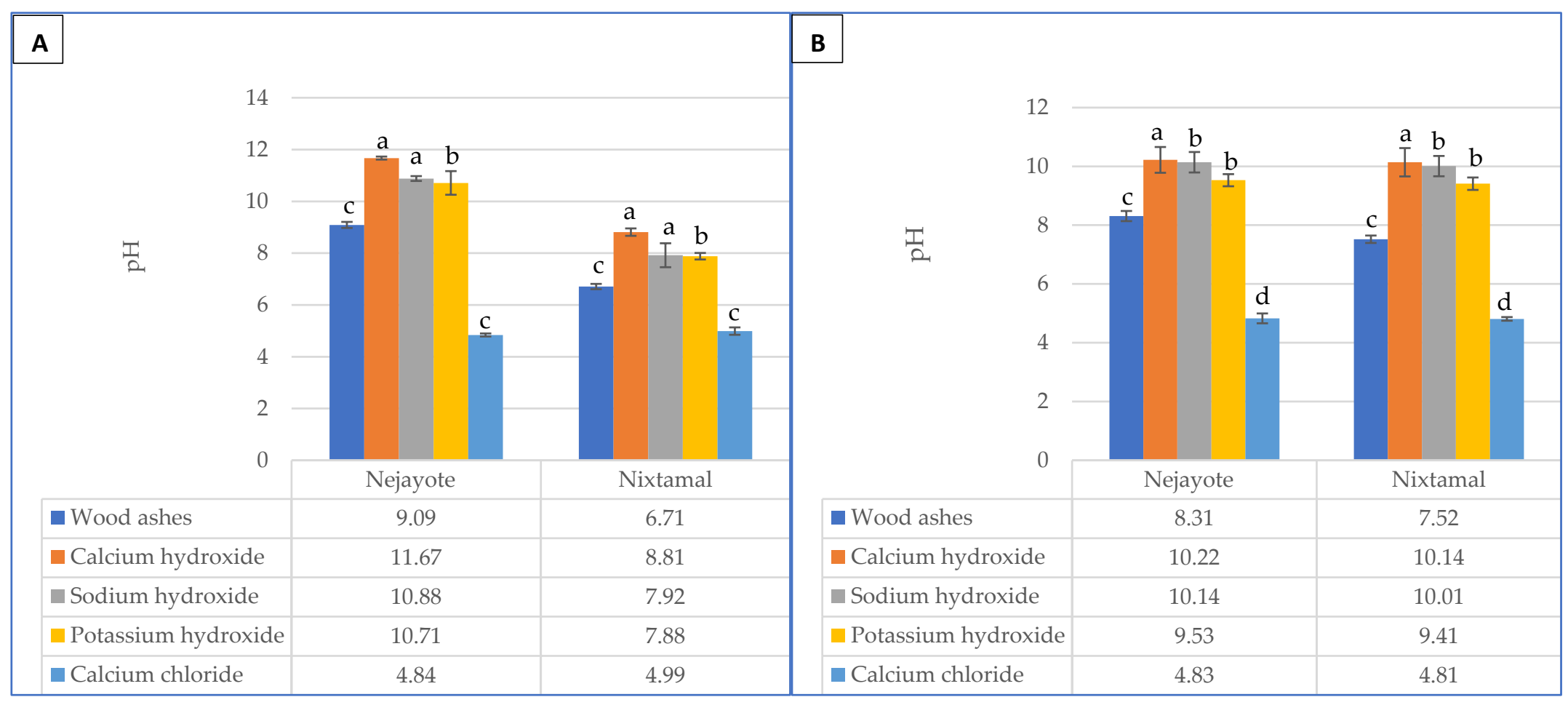

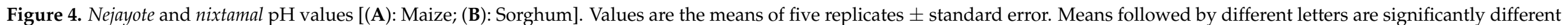
$(p<0.05)$ according to Tukey post-hoc test. 


\subsection{Principal Component Analysis of the Maize and Sorghum Data}

Principal component analysis (PCA) was performed to assess the association between the nixtamalization cooking ingredients and their Fusarium mycotoxins reduction patterns during nixtamalization. The unsupervised clustering method was followed to scrutinize the data structure of the percentage reduction of each Fusarium mycotoxin during the nixtamalization process, establish similarities among different cooking ingredients, and examine the presence or absence of outliers. Two principal components (PCs), i.e., PC1 and PC2, describing approximately $61 \%$ variation in the pareto-scaled data, were generated for the maize nixtamalization process (Figure 5A). PC1 explained $41.1 \%$ of the variance in the use of the different cooking ingredients for nixtamalization, while PC2 explained an additional 19.8\% variation in the reduction of Fusarium mycotoxins when these cooking ingredients for nixtamalization were used. On the score plot (Figure 5A), a distinct separation of nixtamal from potassium hydroxide was observed in quadrant 3 , while that produced from calcium chloride treatment was in the fourth quadrant.

In comparison with the clusters of potassium hydroxide and calcium chloride nixtamal, Figure 5A showed a somewhat close relationship between the clusters of the percentage mycotoxins reduction pattern of wood ashes, calcium hydroxide, and sodium hydroxide. The observed clear separation of some of the clusters reflects the differences in the chemical properties and reactions involved when different cooking ingredients for nixtamalization were used, which in turn led to notable changes in $\mathrm{pH}$ values.

The PCA scores plot of the nixtamalized sorghum samples is presented in Figure 5B. PC1 and PC2 account for $94.3 \%$ of the variation in the nixtamalized sorghum samples data with clear discrimination into two broad clusters. Mycotoxin reduction in the nixtamal cooked with calcium chloride was scattered toward the right, while the nixtamal obtained using other cooking ingredients clustered near the center position, which may be attributed to their similar chemical properties [12].

These clusters from wood ashes, calcium hydroxide, sodium hydroxide, and potassium hydroxide treatments as shown in Figure 5B, to a large extent, also reflect the earlier observed similar ability of these cooking ingredients to reduce FBs in sorghum. In contrast, the nixtamal cooked with calcium chloride showed high variation with major outliers. In line with Girolamo et al. [36], physico-chemical changes that take place in food during nixtamalization, like starch gelatinization, can lead to the release of matrix-associated FBs in the nixtamal. The degree of this gelatinization process depends on the breaking of hydrogen bonds of the hydroxyl groups present in the starch chains. Hence, the dissociation nature of compounds/ingredients used in nixtamalization may significantly affect starch gelatinization [12].

In the current study, calcium hydroxide, sodium hydroxide, and potassium hydroxide used as cooking ingredients for nixtamalization were dissociated into hydroxyl ion $\left(\mathrm{OH}^{-}\right)$, which easily penetrated the starch granule, breaking the hydrogen bonds between water molecules and hydroxyl groups of the starch chains. This then led to an increase in the penetration power of water molecules and an enhanced gelatinization process in samples obtained from these cooking ingredients [12]. For calcium chloride, the gelatinization of starch granules is somewhat reduced as it dissociates into $\mathrm{Cl}^{-}$, which triggers the formation of hydrogen bonds between water molecules while resisting starch hydroxyl groups [17]. Generally, the difference in PCA plots for percentage mycotoxins reduction in maize and sorghum show that the mycotoxin reduction patterns in cereals are a function of their food matrices. 


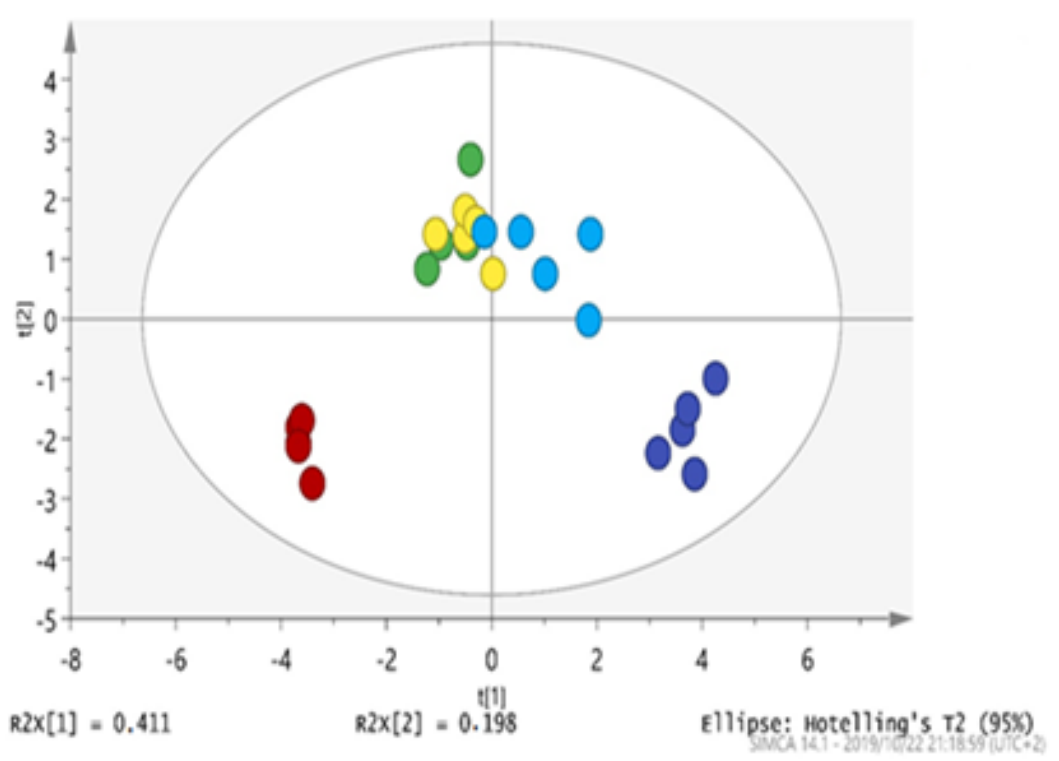

(A)

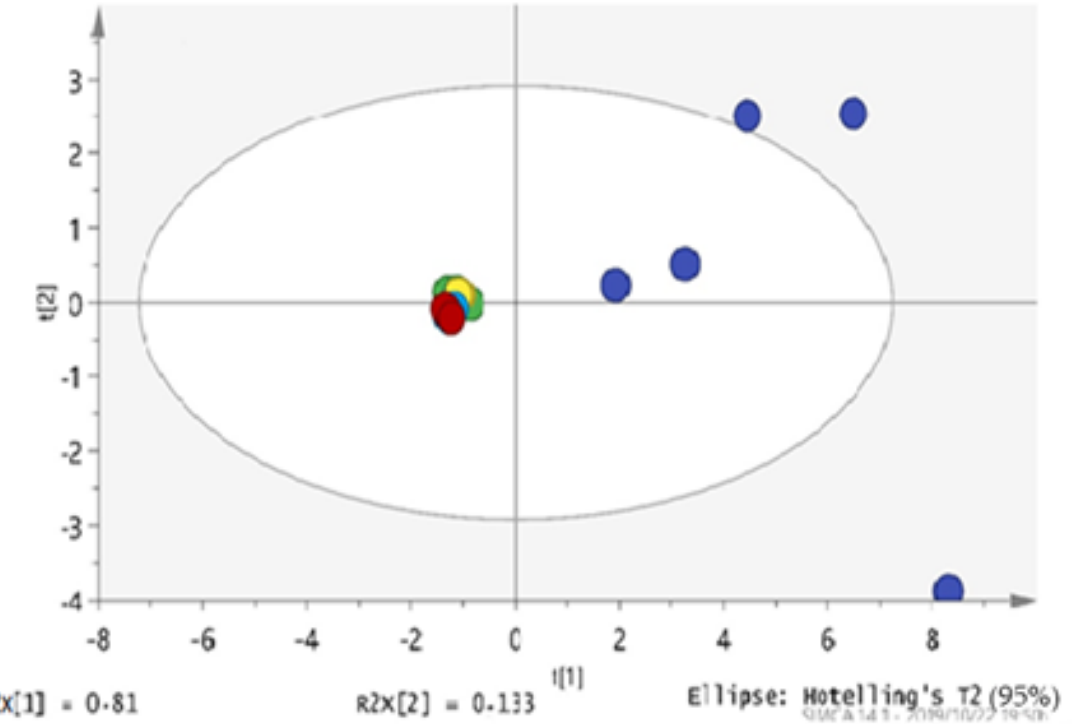

(B)

Figure 5. Investigational data analysis with unsupervised chemometric method, principal component analysis of: (A) Maize samples, and (B) Sorghum samples. 


\section{Conclusions}

This study offers valuable information on the impact of five nixtamalization cooking ingredients on Fusarium mycotoxins reduction in maize and sorghum during nixtamalization. The experimental results revealed that in addition to FBs produced in maize and sorghum grains inoculated with F. verticillioides maintained under similar experimental conditions, other mycotoxins such as DON, NIV, and ZEN were also produced in the inoculated maize sample. Among the tested cooking ingredients for nixtamalization, calcium chloride was generally found to have the least reducing effect on the concentrations of the target mycotoxins in the final maize nixtamal. For sorghum, wood ashes, calcium hydroxide, sodium hydroxide, and potassium hydroxide were also more effective than calcium chloride in reducing FBs. Notwithstanding, the nejayote and nixtamal obtained from maize and sorghum treated with calcium chloride had the lowest $\mathrm{pH}$ values which are within the acidic range.

Overall, the research revealed that sodium hydroxide and potassium hydroxide can be used as alternative nixtamalization cooking ingredients to calcium hydroxide in reducing these FB analogs in contaminated maize and sorghum during nixtamalization. This further supports the use of sodium hydroxide for pre-cooking grains in pozole preparation as practiced in the nixtamalized maize flour industry. Although calcium chloride had the least significant effect on Fusarium mycotoxins reduction in the final nixtamal when compared with other cooking ingredients, it may still be used when there are environmental concerns regarding nejayote disposal. As the levels of parent mycotoxins in the final nixtamal obtained in this study were below the maximum allowable limit by the European Union, future studies are required to assess possible modified/bound/hidden mycotoxin products in the final nixtamal, aside from $\mathrm{N}$-fatty acyl $\mathrm{FB}$, arising from matrix-mycotoxin interaction during nixtamalization for potential identification and toxicity.

\section{Materials and Method}

\subsection{Chemicals and Reagents}

$\mathrm{FB}_{1}, \mathrm{FB}_{2}, \mathrm{DON}$, deepoxy-deoxynivalenol (DOM), NIV, ZEN, and zearalanone (ZAN) standards were purchased from Sigma-Aldrich (Bornem, Belgium), while $\mathrm{FB}_{3}$ was from Promec Unit (Tynberg, South Africa). LC-MS grade methanol, glacial acetic acid, analyticalgrade acetonitrile (Biosolve B. V., Valkenswaard, The Netherlands), analytical-grade methanol, ammonium acetate, formic acid, calcium hydroxide, calcium chloride, sodium hydroxide, potassium hydroxide (Merck, Darmstardt, Germany), dichloromethane, ethyl acetate (Acros Organics, Geel, Belgium), and n-hexane (VWR International, Zaventem, Belgium) were used including ultra-pure water from Arium ${ }^{\circledR}$ pro Ultrapure Water System (Sartorius, Goettingen, Germany). Wood ashes were collected within Ghent environment, Belgium, while GracePure aminopropyl $\left(\mathrm{NH}_{2}\right)$ solid-phase extraction (SPE) $1000 \mathrm{mg} / 6 \mathrm{~mL}$ cartridges were obtained from Grace Discovery Sciences (Lokeren, Belgium).

\subsection{Preparation of the Growth Media and Inoculation of F. Verticillioides Strains}

White maize and sorghum grains purchased at Bio Shop in Ghent, Belgium, were used for the experiment. Inoculation and incubation with $F$. verticillioides strains were achieved using solid potato dextrose agar (PDA) for 7 days at $25^{\circ} \mathrm{C}$ in order to activate the strain. The maize and sorghum media were prepared by pouring $500 \mathrm{~mL}$ of distilled water in $2000 \mathrm{~g}$ of previously analyzed mycotoxin-free maize/sorghum grains. The media were vigorously shaken to avoid clumping, kept overnight, and sterilized in an autoclave for $15 \mathrm{~min}$ at $121^{\circ} \mathrm{C}$. The inoculation procedure as described by Shi et al. [7] and Medina et al. [37] was followed. This involved placing a piece of $4 \mathrm{~mm}$ diameter agar disc taken from the 7-day old colony of the strain grown on PDA at the center of the maize/sorghum media and incubating $\left(25^{\circ} \mathrm{C}\right)$ for 4 weeks. The media were harvested, dried at $40^{\circ} \mathrm{C}$ until a constant weight was obtained, and kept cool prior to the nixtamalization experiment. Inoculated maize and sorghum samples were analyzed for their Fusarium mycotoxins content as described in Sections 4.5 and 4.6 after the 4 weeks incubation. 


\subsection{Processing of Nixtamalized Maize and Sorghum}

The modified method of Villada et al. [38] was used for the nixtamalization process (Figure 6). Samples were prepared by first washing followed by cooking $100 \mathrm{~g}$ of toxigenic fungal-inoculated maize and sorghum grains with $200 \mathrm{~mL}$ purified water.

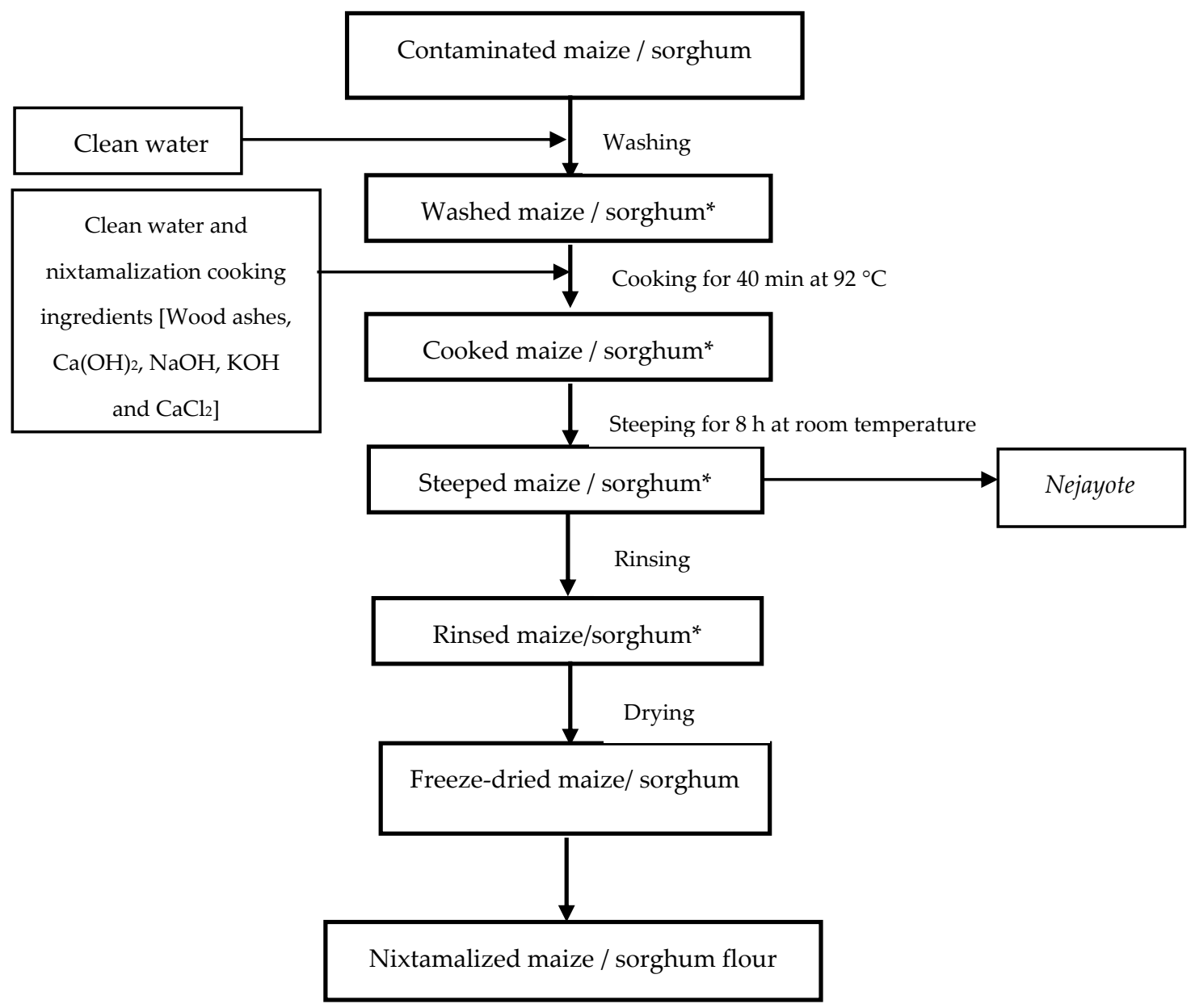

Figure 6. Schematic flow diagram of the nixtamalization of maize/sorghum using different nixtamalization cooking ingredients. (* Points where samples were taken for mycotoxins analysis).

For the cooking process, contaminated maize and sorghum grains were treated with the different cooking ingredients for nixtamalization, i.e., wood ashes, calcium hydroxide, sodium hydroxide, potassium hydroxide, and calcium chloride ( $1 \mathrm{~g}$ each), by cooking at $92{ }^{\circ} \mathrm{C}$ for $40 \mathrm{~min}$ in $400 \mathrm{~mL}$ of water followed by steeping for $8 \mathrm{~h}$ at room temperature and discarding of the cooking liquor. The nixtamal was rinsed twice using purified water (3:1, $w / v)$ for $60 \mathrm{~s}$ followed by freeze-drying using a Ruckwand VaCo 5 Standard freeze dryer (Zirbus Technology, Germany). Thereafter, the dried nixtamal as well as all other samples were milled to fine particle size $(<200 \mu \mathrm{m})$ using an IKA M20 universal mill (Sigma-Aldrich, Bornem, Belgium), thoroughly homogenized, stored, and kept at $-18{ }^{\circ} \mathrm{C}$ prior to analysis.

\subsection{Preparation of Mycotoxin Standard Solution}

Stock solutions of $\mathrm{FB}_{1}, \mathrm{FB}_{2}, \mathrm{FB}_{3}, \mathrm{DON}, \mathrm{NIV}$, ZEN, and ZAN were prepared in methanol at a concentration of $1 \mathrm{mg} / \mathrm{mL}$. DOM $(50 \mu \mathrm{g} / \mathrm{mL})$ was obtained as a solution in acetonitrile. The working standard solutions were prepared by diluting the stock standard solutions in methanol and storing them immediately at $-18^{\circ} \mathrm{C}$. The standard solution mixture of $\mathrm{FB}_{1}$ $(5 \mu \mathrm{g} / \mathrm{mL}), \mathrm{FB}_{2}, \mathrm{FB}_{3}, \mathrm{DON}$ (each $\left.10 \mu \mathrm{g} / \mathrm{mL}\right)$, NIV $(40 \mu \mathrm{g} / \mathrm{mL})$, and ZEN $(2.5 \mu \mathrm{g} / \mathrm{mL})$ was then prepared from the working standard solutions. 


\subsection{Sample Extraction and Clean-Up}

Extraction and clean-up of all the samples were performed following the procedure of Njumbe Ediage et al. [39]. Each sample (3 g) was spiked with internal standards [ZAN $(2.5 \mu \mathrm{g} / \mathrm{mL})$ and DOM $(50 \mu \mathrm{g} / \mathrm{mL})]$ and allowed to equilibrate in the dark for $15 \mathrm{~min}$. Twenty milliliters of extraction solvent [methanol/ethyl acetate/water $(70 / 20 / 10, v / v / v)$ ] were added to each sample. The mixture was vortexed, agitated for $40 \mathrm{~min}$ using an overhead shaker (Agitelec, Paris, France), centrifuged for $10 \mathrm{~min}$ at $4000 \times g$, and the supernatant transferred into a new centrifuge tube. Ten milliliters of $n$-hexane was added to the supernatant and defatting performed by agitation and centrifugation. The lower phase of the solution was subjected to solid-phase extraction (SPE) and the upper phase (n-hexane layer) discarded.

SPE involved purification using GracePure amino SPE cartridges. Due to the strong binding capability of the carboxylic acid functional groups of FBs to the resin of the amino SPE cartridges, the defatted extract was divided into two portions and subjected to different clean-up procedures. Each defatted extract $(2.5 \mathrm{~mL})$ was transferred to a centrifuge tube containing a $10 \mathrm{~mL}$ solution of dichloromethane/formic acid $(95 / 5, v / v)$, vortexed, and centrifuged at $4000 \times g$ for $10 \mathrm{~min}$. Thereafter, $12.5 \mathrm{~mL}$ part of the defatted extract was passed through an amino SPE (GracePure, $1000 \mathrm{mg}$ ) column, fixed on a vacuum elution manifold previously pre-conditioned with $10 \mathrm{~mL}$ of the extraction solvent. The eluate from the SPE was collected in a glass test tube. Both portions of the cleaned extracts in the dichloromethane/formic acid solution and after amino SPE clean-up were combined and evaporated at $40^{\circ} \mathrm{C}$ to dryness using nitrogen gas at a gentle flow rate. The residue was reconstituted in $300 \mu \mathrm{L}$ of mobile phase containing equal volumes of mobile phase $\mathrm{A}$ [water/methanol/acetic acid $(94 / 5 / 1, v / v / v)+5 \mathrm{mM}$ ammonium acetate $(0.385 \mathrm{~g} / \mathrm{L})$ ] and mobile phase B [water/methanol/ acetic acid $(2 / 97 / 1, v / v / v)+5 \mathrm{mM}$ ammonium acetate $(0.385 \mathrm{~g} / \mathrm{L})]$ mixed with $200 \mu \mathrm{L}$ of $\mathrm{n}$-hexane. Prior to injection in the LC-MS/MS, the reconstituted extract was centrifuged for $10 \mathrm{~min}$ at $1000 \mathrm{~g}$ and further filtered using Ultra free PVDF centrifuge filters with a pore size of $0.22 \mu \mathrm{m}$ (Millipore Bedford, MA, USA).

\subsection{Liquid Chromatography-Tandem Mass Spectrometry}

Identification and quantification of Fusarium mycotoxins were performed on a Waters Acquity UPLC apparatus paired to a Quattro premier XE Tandem Mass Spectrometer (Waters, Milford, MA, USA). The chromatographic conditions were similar to those described by Njumbe Ediage et al. [39] with a C18 column $(150 \mathrm{~mm} \times 2.1 \mathrm{~mm}$ i.d., $5 \mu \mathrm{m})$ preceded by a guard column $(10 \mathrm{~mm} \times 2.1 \mathrm{~mm})$ of similar material (Waters, Zellik, Belgium). The analyte injection volume of $10 \mu \mathrm{L}$ was used with mobile phases $\mathrm{A}$ and $\mathrm{B}$ set at a flow rate of $0.3 \mathrm{~mL} / \mathrm{min}$ following a gradient elution program, and $28 \mathrm{~min}$ run time. The instrument was controlled, and data processed using the Masslynx version 4.1 and Quanlynx version 4.1 software (Manchester, UK). Limits of detection (LOD) and quantitation (LOQ) were established at 3.33 and 10 times the signal/noise ratio, respectively.

\subsection{Statistical Analysis}

The influence of different nixtamalization cooking ingredients on the reduction of Fusarium mycotoxins in maize and sorghum during nixtamalization was evaluated. An independent-sample $T$-test was performed where applicable while One-way analysis of variance (ANOVA) (SPSS ${ }^{\circledR}$, v26, IBM Statistics for Windows, New York, NY, USA) of the results at 95\% confidence level was carried out with Tukey's test for the post-hoc analysis. In addition, Soft Independent Modelling of Class Analogy (SIMCA) software (version 14.1 Umetrics; Umea, Sweden) was used for the principal component analysis of the data obtained.

Author Contributions: Conceptualization, J.O.O., S.D.S., M.D.B., G.O.A., S.C., G.A., and P.B.N.; methodology, J.O.O., S.D.S., M.D.B., G.O.A., K.A., and P.B.N.; software, J.O.O., S.G., and K.V.; validation, J.O.O.; formal analysis, J.O.O., K.V., and S.G.; investigation, J.O.O.; resources, S.D.S., 
M.D.B., G.O.A., K.A., and P.B.N.; data curation, J.O.O., S.D.S., M.D.B., G.O.A., and P.B.N.; writingoriginal draft preparation, J.O.O.; writing—review and editing, J.O.O., S.D.S., M.D.B., G.O.A., K.A., S.C., G.A., K.V., S.G., and P.B.N.; visualization, J.O.O.; supervision, S.D.S., M.D.B., G.O.A., and P.B.N.; project administration, S.D.S., M.D.B., G.O.A., S.C., G.A., and P.B.N.; funding acquisition, S.D.S., M.D.B., G.O.A., S.C., G.A., and P.B.N. All authors have read and agreed to the published version of the manuscript.

Funding: This research was financially supported by the South African National Research Foundation via the NRF-TWAS African Renaissance Doctoral Scholarship for research (UID:110910) and NRFLEAP Agri MycoSafe-South funding to Julianah Olayemi Odukoya, the main author.

Institutional Review Board Statement: Not applicable.

Informed Consent Statement: Not applicable.

Data Availability Statement: The data presented in this study are available on request from the corresponding authors.

Acknowledgments: This research was conducted within the ERA-NET LEAP-Agri MycoSafe-South and MYTOX-SOUTH project with the financial support of the South African National Research Foundation (NRF)—The World Academy of Sciences (TWAS). The authors acknowledge Christ'l Detavernier, Mario Van de Velde, and Frédéric Dumoulin of the Centre of Excellence in Mycotoxicology and Public Health, Ghent University, Belgium, for their technical assistance.

Conflicts of Interest: The authors declare no conflict of interest.

\section{References}

1. Chilaka, C.A.; De Boevre, M.; Atanda, O.O.; De Saeger, S. Occurrence of Fusarium mycotoxins in cereal crops and processed products (Ogi) from Nigeria. Toxins 2016, 8, 342. [CrossRef] [PubMed]

2. Streit, E.; Schwab, C.; Sulyok, M.; Naehrer, K.; Krska, R.; Schatzmayr, G. Multi-mycotoxin screening reveals the occurrence of 139 different secondary metabolites in feed and feed ingredients. Toxins 2013, 5, 504-523. [CrossRef] [PubMed]

3. Wagacha, J.M.; Muthomi, J.W. Mycotoxin problem in Africa: Current status, implications to food safety and health and possible management strategies. Int. J. Food Microbiol. 2008, 124, 1-12. [CrossRef] [PubMed]

4. Misihairabgwi, J.M.; Ezekiel, C.N.; Sulyok, M.; Shephard, G.S.; Krska, R. Mycotoxin contamination of foods in Southern Africa: A 10-year review (2007-2016). Crit. Rev. Food Sci. Nutr. 2019, 59, 43-58. [CrossRef]

5. Gbashi, S.; Madala, N.E.; De Seager, S.; De Boevre, M.; Adekoya, I.O.; Adebo, O.A.; Njobeh, P.B. The socio-economic impact of mycotoxin contamination in Africa. In Fungi and Mycotoxins-Their Occurrence, Impact on Health and the Economy as Well as Preand Postharvest Management Strategies; Njobeh, P.B., Stepman, F., Eds.; InTech: Rijeka, Croatia, 2018.

6. Njobeh, P.B.; Dutton, M.F.; Åberg, A.T.; Haggblom, P. Estimation of multi-mycotoxin contamination in South African compound feeds. Toxins 2012, 4, 836-848. [CrossRef]

7. Shi, W.; Tan, Y.; Wang, S.; Gardiner, D.M.; De Saeger, S.; Liao, Y.; Wang, C.; Fan, Y.; Wang, Z.; Wu, A. Mycotoxigenic potentials of Fusarium species in various culture matrices revealed by mycotoxin profiling. Toxins 2017, 9, 6. [CrossRef]

8. Luo, Y.; Liu, X.; Li, J. Updating techniques on controlling mycotoxins-A review. Food Control 2018, 89, 123-132. [CrossRef]

9. Figueroa, J.D.C.; Véles-Medina, J.J.; Tolentino-Lõpez, E.M.; Gaytán-Martínez, M.; Aragõn-Cuevas, F.; Palacios, N.; Willcox, M. Effect of traditional nixtamalization process on starch annealing and the relation to pozole quality. J. Food Process Eng. 2013, 36, 704-714. [CrossRef]

10. Schaarschmidt, S.; Fauhl-Hassek, C. Mycotoxins during the processes of nixtamalization and tortilla production. Toxins 2019, 11, 227. [CrossRef]

11. Escalante-Aburto, A.; Mariscal-Moreno, R.M.; Santiago-Ramos, D.; Ponce-García, N. An update of different nixtamalization technologies, and its effects on chemical composition and nutritional value of corn tortillas. Food Rev. Int. 2019, 36, 456-498. [CrossRef]

12. Santiago-Ramos, D.; Figueroa-Cárdenas, J.d.D.; Mariscal-Moreno, R.M.; Escalante-Aburto, A.; Ponce-García, N.; Véles-Medina, J.J Physical and chemical changes undergone by pericarp and endosperm during corn nixtamalization-A review. J. Cereal Sci. 2018, 81, 108-117. [CrossRef]

13. Figueroa, J.d.D.; Véles Medina, J.J.; Hernández Landaverde, M.A.; Aragón Cuevas, F.; Gaytán Martínez, M.; Chávez Martínez, E.; Palacios, N.; Willcox, M. Effect of annealing from traditional nixtamalisation process on the microstructural, thermal, and rheological properties of starch and quality of pozole. J. Cereal Sci. 2013, 58, 457-464. [CrossRef]

14. Ramírez-Jiménez, A.K.; Rangel-Hernández, J.; Morales-Sánchez, E.; Loarca-Piña, G.; Gaytán-Martínez, M. Changes on the phytochemicals profile of instant corn flours obtained by traditional nixtamalization and ohmic heating process. Food Chem. 2019, 276, 57-62. [CrossRef] [PubMed]

15. Ramírez-Araujo, H.; Gaytán-Martínez, M.; Reyes-Vega, M.L. Alternative technologies to the traditional nixtamalization process: Review. Trends Food Sci. Technol. 2019, 85, 34-43. [CrossRef] 
16. Enríquez-Castro, C.M.; Torres-Chávez, P.I.; Ramírez-Wong, B.; Quintero-Ramos, A.; Ledesma-Osuna, A.I.; López-Cervantes, J.; Gerardo-Rodríguez, J.E. Physicochemical, rheological, and morphological characteristics of products from traditional and extrusion nixtamalization processes and their relation to starch. Int. J. Food Sci. 2020, 2020, 5927670. [CrossRef]

17. Santiago-Ramos, D.; Figueroa, J.D.D.; Juan, V.; Ramos, M.; Gayt, M.; Morales, E. Effects of annealing and concentration of calcium salts on thermal and rheological properties of maize starch during an ecological nixtamalization process. Cereal Chem. 2015, 92, 475-480. [CrossRef]

18. Vázquez-Carrillo, M.G.; Santiago-Ramos, D.; Domínguez-Rendón, E.; Audelo-Benites, M.A. Effects of two different Pozole preparation processes on quality variables and pasting properties of processed maize grain. J. Food Q. 2017, 2017, 1-15. [CrossRef]

19. Ranum, P.; Peña-Rosas, J.P.; Garcia-Casal, M.N. Global maize production, utilization, and consumption. Ann. N. Y. Acad. Sci. 2014, 1312, 105-112. [CrossRef]

20. Pereira, V.L.; Fernandes, J.O.; Cunha, S.C. Mycotoxins in cereals and related foodstuffs: A review on occurrence and recent methods of analysis. Trends Food Sci. Technol. 2014, 36, 96-136. [CrossRef]

21. Hassan, Z.U.; Al-Thani, R.F.; Migheli, Q.; Jaoua, S. Detection of toxigenic mycobiota and mycotoxins in cereal feed market. Food Control 2018, 84, 389-394. [CrossRef]

22. Oldenburg, E. Fusarium diseases of maize associated with mycotoxin contamination of agricultural products intended to be used for food and feed. Mycotoxin Res. 2017. [CrossRef] [PubMed]

23. Karlovsky, P.; Suman, M.; Berthiller, F.; De Meester, J.; Eisenbrand, G.; Perrin, I.; Oswald, I.P.; Speijers, G.; Chiodini, A.; Recker, T.; et al. Impact of food processing and detoxification treatments on mycotoxin contamination. Mycotoxin Res. 2016, 32, 179-205. [CrossRef] [PubMed]

24. Mayer, E.; Novak, B.; Springler, A.; Schwartz-Zimmermann, H.E.; Nagl, V.; Reisinger, N.; Hessenberger, S.; Schatzmayr, G. Effects of deoxynivalenol (DON) and its microbial biotransformation product deepoxy-deoxynivalenol (DOM-1) on a trout, pig, mouse, and human cell line. Mycotoxin Res. 2017, 33, 297-308. [CrossRef] [PubMed]

25. Humpf, H.U.; Voss, K.A. Effects of thermal food processing on the chemical structure and toxicity of fumonisin mycotoxins. Mol. Nutr. Food Res. 2004, 48, 255-269. [CrossRef]

26. Matumba, L.; Van Poucke, C.; Njumbe Ediage, E.; Jacobs, B.; De Saeger, S. Effectiveness of hand sorting, flotation/washing, dehulling and combinations thereof on the decontamination of mycotoxin-contaminated white maize. Food Addit. Contam. Part A 2015, 32, 960-969. [CrossRef]

27. Fandohan, P.; Zoumenou, D.; Hounhouigan, D.J.; Marasas, W.F.O.; Wingfield, M.J.; Hell, K. Fate of aflatoxins and fumonisins during the processing of maize into food products in Benin. Int. J. Food Microbiol. 2005, 98, 249-259. [CrossRef]

28. Shetty, P.H.; Bhat, R.V. A physical method for segregation of fumonisin-contaminated maize. Food Chem. 1999, 66, 371-374. [CrossRef]

29. Park, J.W.; Scott, P.M.; Lau, B.P.Y. Analysis of N-fatty acyl fumonisins in alkali-processed corn foods. Food Sci. Biotechnol. 2013, 22, 147-152. [CrossRef]

30. Fandohan, P.; Ahouansou, R.; Houssou, P.; Hell, K.; Marasas, W.F.O.; Wingfield, M.J. Impact of mechanical shelling and dehulling on Fusarium infection and fumonisin contamination in maize. Food Addit. Contam. 2006, 23, 415-421. [CrossRef]

31. Ryu, D.; Jackson, L.S.; Bullerman, L.B. Effects of Processing on Zearalenone. In Mycotoxins and Food Safety. Advances in Experimental Medicine and Biology; De Vries, J.W., Trucksess, M.W., Jackson, L.S., Eds.; Springer: Boston, MA, USA, 2002; Volume 504, pp. 205-216. [CrossRef]

32. Freire, L.; Sant'Ana, A.S. Modified mycotoxins: An updated review on their formation, detection, occurrence, and toxic effects. Food Chem. Toxicol. 2018, 111, 189-205. [CrossRef]

33. Hernández-Becerra, E.; Gutierrez-Oñate, M.P.; Martinez-Soto, G.; Vega-Rojas, L.J.; Acosta-Osorio, A.A.; Contreras-Padilla, M.; Rodríguez-García, M.E. Physicochemical characterization of corn-sorghum nixtamalized flours as a function of the steeping time. J. Food Measur. Charact. 2016, 10, 434-443. [CrossRef]

34. Jackson, D.S.; Sahai, D.U.S. Enzymatic Process for Nixtamalization of Cereal Grains. U.S. Patent No. 6,428,828, 6 August 2002.

35. Pappa, M.R.; de Palomo, P.P.; Bressani, R. Effect of lime and wood ash on the nixtamalization of maize and tortilla chemical and nutritional characteristics. Plant Foods Hum. Nutr. 2010, 65, 130-135. [CrossRef] [PubMed]

36. De Girolamo, A.; Lattanzio, V.M.T.; Schena, R.; Visconti, A.; Pascale, M. Effect of alkaline cooking of maize on the content of fumonisins B1 and B2 and their hydrolysed forms. Food Chem. 2016, 192, 1083-1089. [CrossRef] [PubMed]

37. Medina, A.; Magan, N. Temperature and water activity effects on production of T-2 and HT-2 by Fusarium langsethiae strains from north European countries. Food Microbiol. 2011, 28, 392-398. [CrossRef] [PubMed]

38. Villada, J.A.; Sánchez-Sinencio, F.; Zelaya-Ángel, O. Gutiérrez-Cortez, E.; Rodríguez-García, M.E. Study of the morphological, structural, thermal, and pasting corn transformation during the traditional nixtamalization process: From corn to tortilla. J. Food Eng. 2017, 212, 242-251. [CrossRef]

39. Njumbe Ediage, E.; Van Poucke, C.; De Saeger, S. A multi-analyte LC-MS/MS method for the analysis of 23 mycotoxins in different sorghum varieties: The forgotten sample matrix. Food Chem. 2015, 177, 397-404. [CrossRef] 